\section{$\underset{\text { hommes }}{\text { \& migrations }}$}

\section{Hommes \& migrations}

Revue française de référence sur les dynamiques

migratoires

$1298 \mid 2012$

France - Algérie, le temps du renouveau

\title{
En finir avec la guerre
}

Films documentaires de Mehdi Lalloui

\section{Anaïs Vincent}

\section{Q OpenEdition \\ 1 Journals}

\section{Édition électronique}

URL : http://journals.openedition.org/hommesmigrations/1596

DOI : 10.4000/hommesmigrations.1596

ISSN : 2262-3353

\section{Éditeur}

Musée national de l'histoire de l'immigration

\section{Édition imprimée}

Date de publication : 1 juillet 2012

Pagination : 156-157

ISSN : 1142-852X

\section{Référence électronique}

Anaïs Vincent, «En finir avec la guerre », Hommes \& migrations [En ligne], 1298 | 2012, mis en ligne le

29 mai 2013, consulté le 22 septembre 2020. URL : http://journals.openedition.org/

hommesmigrations/1596; DOI : https://doi.org/10.4000/hommesmigrations.1596

Ce document a été généré automatiquement le 22 septembre 2020.

Tous droits réservés 


\title{
En finir avec la guerre
}

\author{
Films documentaires de Mehdi Lalloui
}

\section{Anaïs Vincent}

À l'occasion du cinquantième anniversaire de la proclamation de l'indépendance de l'Algérie, l'association Au nom de la mémoire qui travaille depuis quinze ans notamment sur la question coloniale, en éditant des ouvrages et en organisant des débats, sort un coffret DVD intitulé En finir avec la guerre. Il comprend cinq documentaires consacrés à la guerre d'Algérie : Porteur d'espoir, Le Manifeste des 121, Le Parfum de ma terre, En finir avec la guerre, Vu de l'autre côté. Le documentariste Mehdi Lallaoui, né à Argenteuil, issu de l'immigration algérienne, a recueilli la parole des acteurs de ce drame. Des deux côtés de la Méditerranée, des hommes et des femmes racontent leur guerre. Chacun de ces films s'articule autour d'un ou plusieurs récits de vie. Loin de tout manichéisme, ces témoignages révèlent la complexité du conflit. Jacques Charby, comédien engagé au sein du réseau Jeanson comme "porteur de valises", explique comment la résistance agissait en métropole et comment ces acteurs de l'ombre parvenaient à venir en aide au FLN au péril de leur vie, devenant ainsi des “ porteurs d'espoir". Parallèlement à ces actions, le Manifeste des 121 fit grand bruit en septembre 1960 et permit d'alerter une partie de l'opinion publique. Qui étaient ces signataires? Qui étaient ces lettrés qui prônaient la ruine du système colonial? Les intellectuels engagés témoignent et reviennent sur la genèse de cette pétition. Et sur le sol algérien, comment cette guerre fut-elle vécue par certains pieds-noirs? Jacky Malléa est l'un d'entre eux. Ce fils de boucher de la petite ville de Guelma raconte son enfance, ses souvenirs teintés des "parfums de sa terre", ses amitiés, son incompréhension face aux événements et la découverte bien plus tard de sa mère biologique. Si beaucoup décidèrent de fermer les yeux sur les atrocités perpétrées par les forces armées, d'autres y participèrent activement. Les membres de l'association des Anciens appelés en Algérie et leurs Amis contre la guerre (4ACG) brisent les tabous en revenant sur leur implication, sur la barbarie, la torture, les exécutions dont ils ont été témoins et parfois même acteurs. Aujourd'hui, ils essaient, par leur action, de retisser des liens avec ce pays pour enfin "en finir avec cette guerre".En contrepoint, l'historien Mohamed Harbi, ancien responsable clandestin du FLN en France, explique comment 
était vécue la guerre "de l'autre côté". Quelles étaient les motivations des combattants du FLN et leur stratégie?

\section{Les mémoires vives de la guerre}

2 En enregistrant la parole des acteurs des différents "camps" et en rompant ainsi le silence, cette série de documentaires pose la question de l'intégration de toutes les mémoires dans la République. Peut-on parvenir à l'élaboration d'une histoire commune? Comment en finir avec cette guerre? Comment mettre au jour, exhumer les atrocités vécues sur les deux continents et les dépasser pour ne pas sombrer dans une victimisation des témoins et de leurs descendants, pour éviter de basculer vers un communautarisme tout aussi néfaste que l'oubli? Comment lutter contre le cloisonnement des souvenirs de chaque groupe? Cinquante ans plus tard, le désir de révéler l'implication de l'État français et la réalité de l'abjection des tortures devient imminent. Si la première génération d'immigrés devait se battre pour sa survie et son travail, la seconde commença à s'interroger sur son passé et sur les douleurs enfouies de ses aïeux. La troisième, encore aujourd'hui victime de discrimination, ne comprend pas pourquoi elle n'est toujours pas intégrée et ne peut le tolérer. Dans cette France multiculturelle, faire le point sur le passé colonial et peu glorieux de l'hexagone est une nécessité. La mise à disposition de ces riches témoignages y contribue. L'histoire personnelle documente l'histoire collective. 1880, l'Algérie devient une colonie de peuplement française. Ses habitants sont relégués au rang d'indigènes, privés de droit. Le colon s'accapare les terres sous couvert d'idéaux républicains qui fondent cette "mission civilisatrice" initiée par la figure tutélaire de Jules Ferry. Elle met en place un système qui permet l'exploitation du pays colonisé en médiatisant les actions humanitaires des militaires. Ce modèle perdurera pendant des décennies. Les anciens appelés se souviennent soixante ans plus tard du petit livret qu'on leur avait remis détaillant leur mission. De bienfaiteurs, ils passent, incrédules, dans une vision cauchemardesque, au rôle de bourreau. Mais, bénéficiant des différentes amnisties, ces acteurs ne seront réellement jamais jugés.

\section{Lutter contre l'oubli}

3 Benjamin Stora rappelle la définition du terme "amnistie" : décision politique qui suspend les sanctions pénales. Elle fut inventée par les Grecs au IVe siècle avant J-C. Le mot mêle les racines des termes "pardon" (amnêstia) et "oubli" (amnêstos). Cette absence de sanction, l'injustice face à ces crimes de barbarie jamais qualifiés de crimes contre l'humanité, a sans doute contribué à cette amnésie collective. Le verbe "occulter" est récurrent dans la bouche de ces anciens appelés qui ont préféré s'enfermer dans le silence jusqu'à l'âge de leur retraite. Avec l'inactivité de leurs vieux jours, les souvenirs sont devenus plus prégnants, obsédants. En émane une culpabilité insoutenable. Mais ces bourreaux n'étaient-ils pas les victimes d'un engrenage militaire bien huilé ? Souvent sans expérience, ces jeunes se sont retrouvés désemparés face à cette violence inhumaine. Et malgré l'atrocité des faits racontés transpire encore leur humanité. Les témoignages de ces anciens appelés entrent en résonnance avec ceux d'anciens membres du FLN qui expliquent leurs motivations. Animés par le noble idéal de la démocratie, ils se battaient pour le rétablissement de la justice. En infériorité 
numéraire, comment pouvaient-ils agir efficacement? Les actions ponctuelles, d'une violence inouïe, qu'ils organisèrent semblaient les seules réponses possibles. Comment se faire entendre autrement? Quelle pouvait être leur défense face à l'oppresseur ? La diversité des points de vue recueillis fait apparaître l'absurdité de la guerre. Grâce à ce genre d'entreprises, comme l'édition de ce coffret ou la réalisation du site www.memoires-algerie.org initié par le quotidien El Watan en collaboration avec OWNI, le processus mémoriel freiné par l'amnésie volontaire de l'État français pourra-t-il enfin partiellement s'opérer?

\section{BIBLIOGRAPHIE}

En finir avec la guerre, de Mehdi Lallaoui, Coffret de 5 DVD (Au nom de la mémoire/Médiapart)

Benjamin Stora, entretiens avec Thierry Leclère, La Guerre des mémoires, la France face à son passé colonial, La Tour d'Aigues, L'Aube, 2007.

Benjamin Stora, Ils venaient d'Algérie, l'immigration algérienne en France 1912-1992, Paris, Fayard, 1992. 